\title{
Arsenic mobilization and retention mechanisms along an iron mineral dominated redox gradient in delta sediments of Van Phuc, Vietnam
}

\author{
M. SCHNEIDER ${ }^{1}$, E. STOPELLI ${ }^{2}$, M. \\ GLODOWSKA $^{3}$, B. RATHI ${ }^{4}$, E. EICHE ${ }^{1}$, A.

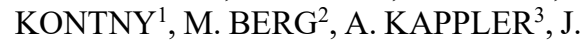 \\ GÖTTLICHER ${ }^{1}$, L. H. E. WINKEL ${ }^{2}$, B.C. BOSTICK ${ }^{4}$, A. \\ NGHIEM $^{6}$, T. NEUMANN ${ }^{7}$ \& ADVECTAS-GROUP \\ ${ }^{1}$ Karlsruhe Institute of Technology, 76131 Karlsruhe, \\ Germany \\ ${ }^{2}$ Swiss Federal Institute of Aquatic Science and Technology, \\ 8600 Dübendorf, Switzerland \\ ${ }^{3}$ Geomicrobiology, Center for Applied Geosciences, \\ University of Tübingen, 72076 Tübingen, Germany; \\ ${ }^{4}$ CSIRO, 6014 Floreat, Australia \\ ${ }^{5}$ Lamont-Doherty Earth Observatory, Columbia University, \\ New York, United States \\ ${ }^{6}$ Key Laboratory of Analytical Technology for \\ Environmental Quality and Food Safety Control \\ (KLATEFOS), University of Science, Hanoi, Vietnam \\ ${ }^{7}$ Technical University Berlin, 10587 Berlin, Germany
}

Iron $(\mathrm{Fe})$ minerals are highly reactive and play a major role in controlling the contaminant dynamics in natural environments. In particular, the behaviour of oxyanions like arsenic (As) in near surface aquifers is known to be controlled by redox-sensitive iron phases. In this regard, we investigated $\mathrm{Fe}$ mineralogy along a redox gradient within the delta sediments of the Red River in Vietnam, which is known for its patchy distribution of dissolved groundwater As. Despite extensive research investigating As mobilization in the context of redox changes, there is a lack of studies analysing geochemical and mineralogical alterations of ferruginous As host phases in-situ. In this study, a sediment core $(50 \mathrm{~m})$ across a redox transition zone (RTZ) was analysed to identify As release and retention mechanisms in relation to iron mineralogy. 